\title{
Primary central nervous system diffuse large B-cell lymphoma in the immunocompetent: Immunophenotypic subtypes and Epstein-Barr virus association
}

\author{
Anita Mahadevan, Clementina Rama Rao', M. Shanmugham¹, Susarla Krishna Shankar \\ Department of Neuropathology, National Institute of Mental Health and Neurosciences, ${ }^{1}$ Department of Pathology, Kidwai Memorial Institute of \\ Oncology, Bangalore, Karnataka, India
}

\begin{abstract}
Introduction: Primary central nervous system diffuse large B-cell lymphoma (PCNSL DLBCL) in the immunocompetent is an uncommon tumor that has an activated B-cell immunophenotype resembling germinal center exit B cells. They also differ from primary central nervous diffuse large B-cell lymphomas in the immunocompromised as they show no association with the Epstein-Barr virus. Objective: To determine if immunophenotypic subtyping of PCNS DLBCL from Asian subcontinent are also different similar to its systemic counterpart is unclear, as there are only limited studies from Asia, and none from India. Material and Methods: The immunohistochemical profile of 24 South Indian patients with primary central nervous system diffuse large B-cell lymphoma was studied using germinal center markers - CD10 and Bcl-6, and activation markers - MUM1 and CD138, which are markers for late/post germinal centre B cells. Insitu hybridization for EBV genome and LMP1 by immunohistochemistry was carried out in all cases to determine association with EBV. Results: Centroblastic morphology and uniform activated B-cell phenotype with positivity for MUM1 was seen in $91.6 \%$ of tumors. Co-expression of Bcl-6 and MUM1 was evident in $50 \%$, which is more frequent than in systemic diffuse large B-cell lymphomas. All cases were negative for Epstein-Barr virus using EBER in-situ hybridization and LMP1 immunohistochemistry. Conclusion: Primary diffuse large B-cell lymphoma in the immunocompetent is a distinct clinicopathological entity with centroblastic morphology, a uniform activated B-cell immunophenotype that is not associated with the Epstein-Barr virus regardless of geographic origin.
\end{abstract}

Key words: Activation markers, diffuse large B cell lymphoma, Epstein-Barr virus, immunophenotype, MUM1, primary central nervous system lymphoma

\section{Introduction}

Primary diffuse large B-cell lymphoma (DLBCL) of the central nervous system (CNS) is an uncommon neoplasm and accounts for $2-3 \%$ of all brain tumors and $<1 \%$ of all non-Hodgkin lymphomas. ${ }^{[1]}$ Primary CNS lymphomas (PCNSL) differ from systemic lymphomas in that they develop in an organ devoid of conventional

\begin{tabular}{|l|l|}
\hline \multicolumn{2}{|c|}{ Access this article online } \\
\hline Quick Response Code: & Website: \\
\hline & www.ruralneuropractice.com \\
\hline & \\
\hline & \\
\hline
\end{tabular}

lymphoid tissue. ${ }^{[2]}$ They are now considered to be a separate entity in the WHO classification of 2008. ${ }^{[1]}$ They have a poorer prognosis than systemic lymphomas of the same subtype, the overall survival in the majority of patients being poor despite novel therapies and improvement in survival for a subgroup of patients with long-term follow up. ${ }^{[3-7]}$ This underlines the need for a better understanding of the molecular pathogenesis of primary DLBCL of the CNS.

Gene expression profiling of systemic DLBCL identified two subgroups of DLBCL, the germinal center B cell (GCB)-like with the profile of germinal centre $B$ cells and the activated $B$ cell-like (ABC-like) with the profile of activated peripheral B cells. ${ }^{[8]} \mathrm{A}$ third subtype (Type 3 ) was added subsequently and found to be heterogeneous. ${ }^{[9]}$ Subtyping of systemic DLBCL

Address for correspondence:

Dr. Anita Mahadevan, Department of Neuropathology, National Institute of Mental Health and Neurosciences, Bangalore - 560 029, Karnataka, India. E-mail: anita_mahadevan@yahoo.com 
by immunohistochemistry has been used extensively by different groups as a more practical alternative to gene expression profiling. Several algorithms have been used to classify DLBCL into germinal center and non-germinal center subtypes with conflicting reports regarding their correlation with gene expression profiles and their utility in predicting survival in the R-CHOP chemotherapeutic era. ${ }^{[10-18]}$ The antibodies used for immunophenotyping of the cells include germinal center markers bcl6 and CD10, and post germinal center (activation) markers MUM1 and CD138 that are markers of late stage of B-cell differentiation. MUM1 is a marker for late germinal center/early post- germinal centre B cells and its expression represents activated (antigen stimulated) GCBs that have the capacity to differentiate toward CD138-expressing plasma cells. ${ }^{[19]}$ Other markers like GCET1, FOXP1, LMO2 and bcl2 have also been included in some algorithms for classification. ${ }^{[20,21]}$

Gene expression profiling studies have indicated that PCNS DLBCL is molecularly heterogeneous, ${ }^{[22,23]}$ including $\mathrm{GCB}, \mathrm{ABC}$ and non- $\mathrm{ABC} / \mathrm{GCB}$ subgroups. In literature, most studies of immunophenotyping of primary central nervous system (CNS) DLBCL have shown a predominantly activated B cell phenotype with almost universal expression of the late germinal center/early post germinal center marker MUM1. ${ }^{[5,6,24-30]}$ The ABC-like phenotype is associated with a worse prognosis in systemic DLBCL by gene expression profiling, ${ }^{[1,8,9]}$ and this has been ascribed as the reason for the poor prognosis in the majority of PCNS DLBCL. ${ }^{[5,6]}$

The immunophenotyping of systemic DLBCL in Asian patients has shown conflicting results, with some studies showing a preponderance of the GCB phenotype and others of the non-GCB phenotype. ${ }^{[31,32]}$ Similarly whether immunophenotypic subtyping of PCNS DLBCL from Asian subcontinent are also different similar to its systemic counterpart is unclear, as there are only limited studies from Asia, ${ }^{[25,26,29,30]}$ and none from India.

The pathogenesis of PCNS DLBCL in the immunocompetent differs from that in the immunocompromised, only $5-10 \%$ of the former being associated with the Epstein-Barr virus (EBV) in contrast to $100 \%$ in systemic DLBCL. ${ }^{[33-38]}$

This study is aimed at determining the immunophenotypic subtypes of PCNS DLBCL in immunocompetent Indian patients and correlates these subtypes with EBV association.

\section{Materials and Methods}

Histologically diagnosed cases of PCNS DLBCL diagnosed between 1991 and 2004 were retrieved from the archives of the Department of Neuropathology at National Institute of Mental Health and Neurosciences, a tertiary referral center for neurological and neurosurgical disorder in Bangalore, India. The study is approved by the Institutional Ethics Committee.

All relevant clinical and demographic details including HIV status were obtained from the case records. Details that may disclose the identity of the patients has been omitted and all cases have been anonymized. Those cases wherein paraffin blocks were available for extended immunophenotyping were included in the study $(n=24)$. The diagnoses of B-cell lymphoma was established by immunostaining with a CD20 marker.

Immunohistochemistry was performed using a standard streptavidin biotin technique. All the cases were subtyped using a panel of antibodies: CD10, bcl6 (GCB markers), MUM1 and C138 (activation markers) [Table 1] with appropriate positive and negative controls.

The immunolabeling was scored based on the percentage positivity of cells in the entire section. Positive staining of more than $30 \%$ of cells of any intensity was considered positive. Slides were considered assessable only if appropriate internal controls were positive.

Subtyping of the lymphomas was carried out using the algorithm of Hans, et al..$^{[10]}$ into GCB type (CD10 + or CD10-/BCL-6+/MUM-1) and non-GCB type. Case was assigned to the GCB type if CD10 alone or CD10 and bcl6 markers were positive. When bcl6 was positive and CD10 negative, reaction to MUM1 determined the subgroup. If MUM1 was positive the case was assigned to the non-GCB group. Subtyping was also performed according to the algorithm of Chang, et al. ${ }^{[11]}$ using activation marker CD138 in addition to CD10, bcl6 and MUM1 into GCB type-type A (only GCB markers positive), activated GCB type-type $B$ (GCB and $A B C$ marker positive) and activated non-GCB type-type $C$ (only $A B C$ markers positive).

In situ hybridization (ISH) to detect EBV genome was carried out in all cases using non-isotopic in-situ hybridization and a fluorescein-labeled oligonucleotide Epstein-Barr encoding region (EBER) probe (Novocastra). Paraffin sections were dewaxed and hydrated, digested with proteinase $\mathrm{K}$ washed in water and air dried. The sections were then hybridized with the fluorescein-labeled EBER probe in hybridization solution for 2 hours at $37^{\circ} \mathrm{C}$. 
Following three washes in TBS-Triton $X$ and incubation for $10 \mathrm{~min}$ with blocking solution, the slides were incubated in an anti-FITC/alkaline phosphatase antibody for 30 minutes. Following washes in TBS and alkaline phosphatase substrate buffer, the slides were incubated with enzyme substrate to visualize the immunoreactions and localize the EBV genome. The sections were counterstained with Meyer's hematoxylin. The sections were considered positive for EBV genome only when more than $10 \%$ of cells had nuclear staining.

\section{Results}

\section{Clinical features}

Twenty-four cases were included in the study [age range: 28-80 years; mean and median age of 53 years; male:female ratio was 1.4:1]. All the patients presented with symptoms and signs related to raised intracranial pressure, abnormal behavior, memory impairment and focal neurological deficits corresponding to the neuroanatomical location of the lesions. All cases were seronegative for HIV-1 and 2. The majority of tumors were supratentorial $(23 / 24)$, the most common site being the frontal lobe (10/24) followed by the temporal (4/24) and parietal (2/24) lobes. Other sites included bifrontal lesions extending across corpus callosum (3), parietooccipital (1), paratrigonal (1) and multicentric periventricular lesions in remainingtwo cases. Midbrain involvement was noted in one case only. Imaging by cranial CT revealed multiple periventricular lesions that were hyperdense and enhancing homogenously on contrast with perilesional edema and mass effect. Following diagnosis, all the patients were referred to Oncology centers for standard chemotherapy. Hence, further clinical details of the patients were not available as they did not come for follow up due to demographic and economic reasons.

\section{Histopathology}

All cases were characterized as diffuse large B-cell lymphomas based on morphology and immunolabeling for B-cell marker, CD20. The tumor cells were present in diffuse sheets or infiltrating through the cerebral parenchyma, with a characteristic angiocentric pattern of arrangement. Twenty-two tumors were centroblastic [Figure 1a] and two tumors were immunoblastic demonstrating prominent nucleoli.

\section{Immunohistochemistry}

All cases were positive for the B-cell marker CD20 [Figure 1b]. A panel of four markers (CD10, bcl6, MUM1 and CD138) was used to classify the tumors into GCB and non-GCB (ABC) subtypes. Among these, 12/24 cases were positive for bcl6, 22 of 24 cases were positive for MUM1, one case was positive for CD138, while all cases were negative for CD10. Two cases were negative for all four markers and could not be further classified [Table 2].

When these tumors were classified according to the Hans classifier, 22/24 cases belonged to the non-GCB subtype, while none were of the germinal center subtype.

Based on Chang's algorithm, 12 cases were type B [activated GCB subtype-positive for both bcl6 and MUM1] [Figure 2a-d], while 10 cases were type C [activated non-GCB subtype: Positive exclusively for MUM1] [Figure 2e-h], and none belonged to type A category (isolated GCB marker positive).

Immunohistochemistry for the latent membrane protein of EBV was negative in all 24 cases. In situ hybridization for EBV was also negative in all cases.

\section{Discussion}

Systemic DLBCL is a heterogeneous entity, both clinically and morphologically. ${ }^{[39]}$ Primary CNS DLBCL though morphologically similar to their systemic

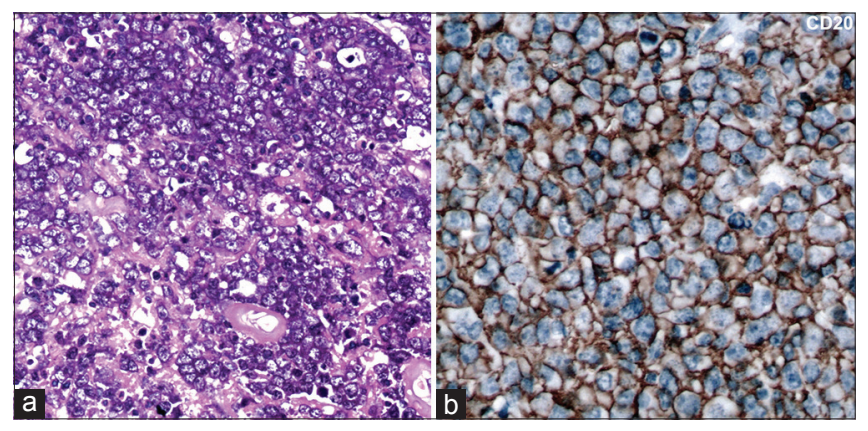

Figure 1: (a) Microphotographs reveal sheets of neoplastic large lymphoid cells with a centroblastic morphology (b) Immunohistochemistry for CD20 reviles strong diffuse membrane positivity in the lymphoma cells $\mathrm{A}=\mathrm{H}$ and $\mathrm{E}, \times 400 \mathrm{~B}=\mathrm{CD} 20$ immunoperoxidase $\times 400$

\section{Table 1: List of antibodies used}

\begin{tabular}{lllll}
\hline & Clone & Source & Antigen retrieval & Dilution \\
\hline CD10 & Mouse monoclonal (56C6) & Novocastra labs, UK & Citrate buffer, pH 6.0 & Ready to use \\
Bc16 & Mouse monoclonal PG $-(\mathrm{B} 6 \mathrm{p})$ & Dako, Denmark & Citrate Buffer, pH 6.0 & $1: 40$ \\
MUM1 & Mouse monoclonal (Mum1 p) & Santa Cruz Biotechnology, California & Citrate pH 6.0 & $1: 30$ \\
CD138 & Mouse monoclonal (MI 15) & Dako, Denmark & Citrate buffer, pH 6.0 & $1: 30$ \\
CD20 & Mouse monoclonal (L26) & Dako, Denmark & Citrate buffer, pH 6.0 & $1: 100$ \\
\hline
\end{tabular}


Table 2: Subtypes of primary CNS diffuse large B cell lymphoma by immunophenotyping $(n=24)$

\begin{tabular}{|c|c|c|c|c|c|c|c|c|c|}
\hline Case no. & Histological type & CD20 & CD10 & Bcl6 & CD138 & MUM1 & IHC subtype & EBER & LMP1 \\
\hline 1 & Centroblastic & + & - & + & - & + & Non GCB, Type B & - & - \\
\hline 2 & Centroblastic & + & - & - & - & + & Non GCB, Type C & - & - \\
\hline 3 & Centroblastic & + & - & + & - & + & Non GCB, Type B & - & - \\
\hline 4 & Centroblastic & + & - & - & - & + & Non GCB, Type C & - & - \\
\hline 5 & Centroblastic & + & - & + & - & + & Non GCB, Type B & - & - \\
\hline 6 & Centroblastic & + & - & + & - & + & Non GCB, Type B & - & - \\
\hline 7 & Centroblastic & + & - & + & - & + & Non GCB, Type B & - & - \\
\hline 8 & Centroblastic & + & - & + & - & + & Non GCB, Type B & - & - \\
\hline 9 & Centroblastic & + & - & + & - & + & Non GCB, Type B & - & - \\
\hline 10 & Centroblastic & + & - & - & - & + & Non GCB, Type C & - & - \\
\hline 11 & Centroblastic & + & - & + & - & + & Non GCB, Type B & - & - \\
\hline 12 & Centroblastic & + & - & - & + & + & Non GCB, Type B & - & - \\
\hline 13 & Centroblastic & + & - & + & - & + & Non GCB, Type C & - & - \\
\hline 14 & Centroblastic & + & - & - & - & + & Non GCB, Type C & - & - \\
\hline 15 & Immunoblastic & + & - & - & - & + & Non GCB, Type C & - & - \\
\hline 16 & Centroblastic & + & - & - & - & - & Non classifiable & - & - \\
\hline 17 & Centroblastic & + & - & - & - & + & Non GCB, Type C & - & - \\
\hline 18 & Centroblastic & + & - & - & - & + & Non GCB, Type C & - & - \\
\hline 19 & Immunoblastic & + & - & + & - & + & Non GCB, Type B & - & - \\
\hline 20 & Centroblastic & + & - & + & - & + & Non GCB, Type B & - & - \\
\hline 21 & Centroblastic & + & - & - & - & + & Non GCB, Type C & - & - \\
\hline 22 & Centroblastic & + & - & - & - & - & Non classifiable & - & - \\
\hline 23 & Centroblastic & + & - & + & - & + & Non GCB, Type B & - & - \\
\hline 24 & Centroblastic & + & - & - & - & + & Non GCB, Type C & - & - \\
\hline
\end{tabular}

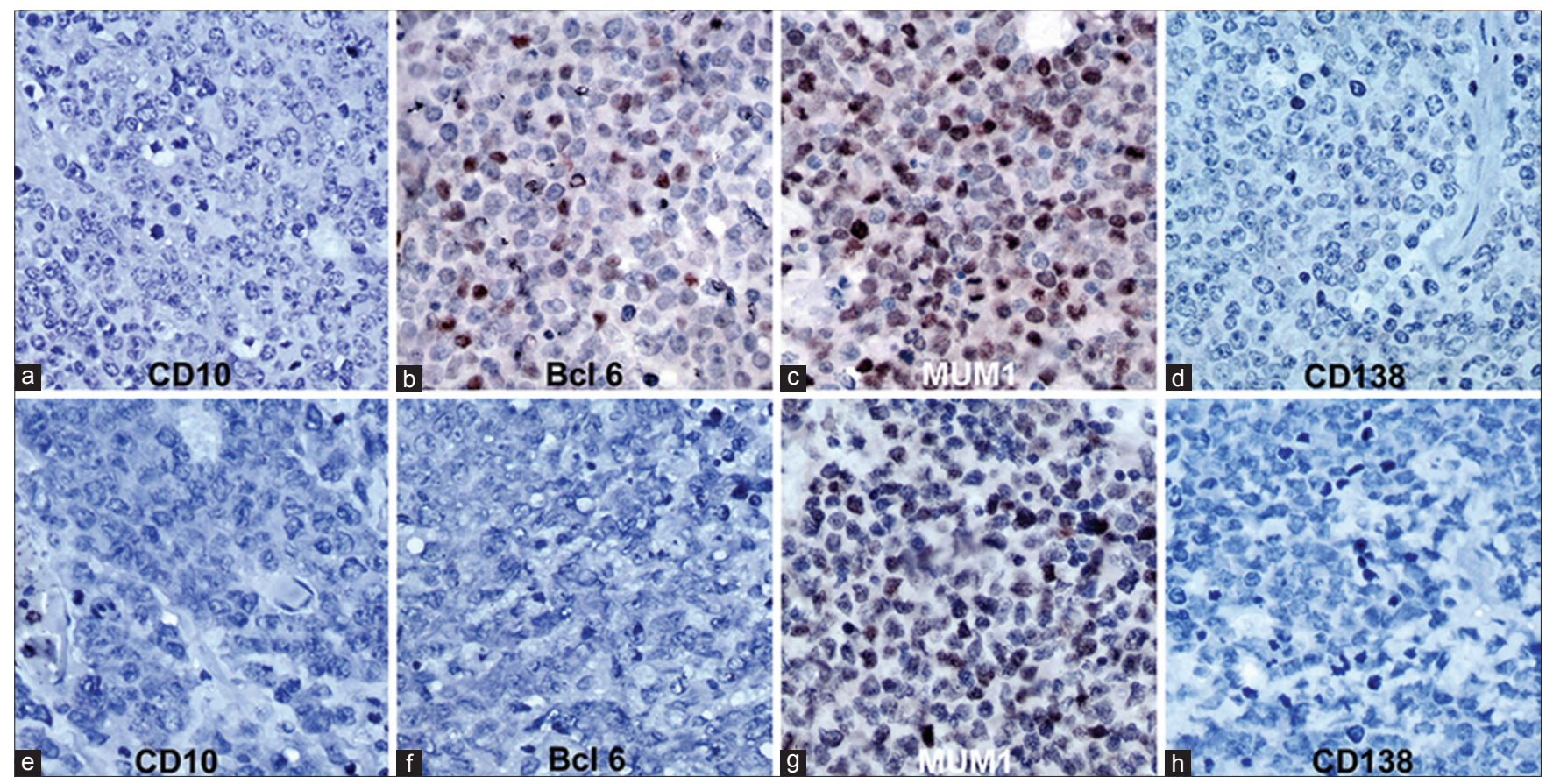

Figure 2: Immunohistochemistry for CD10, Bcl-6, MUM1 and CD138 in primary CNS lymphoma. (a-d) Activated Germinal centre B/Type B pattern (Chang algorithm): CD10-, Bcl-6+, MUM1+, CD138- (Bcl-6 and MUM1 show nuclear positivity in tumor cells). (e-h) Activated non-germinal centre/Type C pattern (Chang algorithm): CD10-, Bcl-6-, MUM1+, CD138- (MUM1 shows nuclear positivity in tumor cells) A-H = Immunoperoxidase $\times 400$

counterparts, has a poor prognosis with overall five year survival of approximately $30 \%$ with the best treatment protocols. ${ }^{[3-7]}$
Recently, systemic diffuse large B-cell lymphomas (DLBCL) have been subcategorized into germinal center and nongerminal center types based on gene 
expression profiles and immunohistochemical expression of CD10, Bcl-6, and MUM1. ${ }^{[8,9]}$ In normal B-cell differentiation, expression of CD10 and Bcl-6 are well-known markers for GCBs, while activation markers include MUM-1 (multiple myeloma-1/interferon regulatory factor-4) and CD138. MUM-1 is a marker for late germinal center/early post-GCBs and its expression represents activated (antigen stimulated)-GCBs that have the capacity to differentiate toward CD138-expressing plasma cells.

Hans, et al. ${ }^{[10]}$ distinguished two subgroups according to the expression of three immunophenotypic markers: CD10, BCL-6, and MUM1. The GCB subgroup included all CD10 + tumors and those with a CD10-/BCL6+/MUM1- immunophenotype. Other patients were assigned to the second group, the non-GCB subgroup, which were defined by MUM1 positivity, regardless of their BCL-6 status (CD10-/BCL-6+/MUM1 + or CD10-/ BCL-6-/MUM1+). Tumors expressing none of the three markers were classified as non-GC types.

Chang's classification ${ }^{[11]}$ was based on two GCB markers, CD10 and BCL-6, and two activation markers, MUM1 and CD138. They defined a GCB pattern (pattern A) that was characterized by positivity for any of the GCB markers (CD10 and/or BCL-6) but no activation marker labeling, an activated GCB pattern (pattern B) expressing at least one GCB and one activation marker, and the activated non-GCB pattern (pattern $\mathrm{C}$ ), expressing activation markers (MUM1 and/or CD138) but none of the GCB proteins. The overall survival of germinal center group is found to be better than the non-germinal center lymphomas.

Immunohistochemical subtyping of systemic DLBCL into GCB and non-GCB subtypes have shown proportions of tumors varying from $65 \% / 35 \%$ to $51 \% / 49 \%$ respectively in various published series. ${ }^{[10-18]}$ There may also be a true biological spectrum reflecting this variability, as seen in pediatric patients in whom there is a marked predominance of the GCB subtype, and also in refractory patients with relapses and in high risk patients. ${ }^{[18]} \mathrm{In}$ contrast, PCNS DLBCL is a relatively homogeneous entity, with a predominantly centroblastic morphology and an $\mathrm{ABC}$ phenotype, with majority of cases showing expression of MUM-1 ${ }^{[5,6,24-30]}$ [Table 3]. In our cases also we found a predominantly $\mathrm{ABC}$ phenotype positive for MUM-1 in $91.6 \%$, and all except two cases revealed centroblastic morphology.

Co-expression of bcl6 and MUM1 is not seen in reactive $\mathrm{B}$ cells where these markers are reciprocally expressed, MUM1 being positive in late centrocytes and plasma cells. MUM1 plays a critical role in downregulating bcl6 expression in normal B-cell development. ${ }^{[42]} \mathrm{On}$ the other hand, co-expression of MUM1 and bcl6 is also a common feature in PCNS DLBCL ${ }^{[5,30]}$ and was observed in $50 \%$ of our cases. Among these lymphomas, CD138, a marker of plasmacytic differentiation is usually negative, indicating an absence of plasmacytic (late post-germinal centre) differentiation. ${ }^{[5,24,25,27]}$ In our series, CD138 was positive in only $1 / 24$ cases. These features suggest an origin of PCNS DLBCL from late germinal centre/early post germinal center exit $B$ cells which have not acquired plasmacytic differentiation.

Asian patients with systemic DLBCL have been shown to have a predominance of GCB origin in some studies and $A B C$ origin in other studies. ${ }^{[1,32,43]}$ This controversy does not seem to reflect in the pattern of primary CNS lymphomas that are uniformly MUM1 positive, indicative of a non-germinal center/ABC phenotype in the studies of Asian patients. ${ }^{[25,26,29,30]}$ In our study, all cases revealed a non-germinal center/ABC phenotype and were uniformly MUM1 positive. Only a small proportion of cases remained non-classifiable as theory were negative for all markers, which is similar to other studies in literature where $4-15 \%$ have remained unclassifiable. ${ }^{[5,6,29]}$

The classification of systemic DLBCL based on gene expression profiling into GCB and APB or type 3 was believed to be of prognostic importance with the GCB group having a significantly better survival than the $A B C$ group, and the type 3 group that had a poor outcome. ${ }^{[8,9]}$ However, the prognostic significance of this classification remains unsubstantiated as available data from various studies are conflicting. Two studies reported a significantly better survival for the GCB group, ${ }^{[29,38]}$ whereas others found no difference in survival between the GCB and non-GCB groups. ${ }^{[28,40,44,45]}$

Studies of prognostic significance of this classification in PCNSL are scarce. In reported studies of PCNSL-DLBCL, $66.7 \%$ to $93 \%$ of the cases belonged to the NGC group..$^{[5,28,40,41]}$ However, all studies till date have uniformly failed to demonstrate a statistically significant difference in terms of overall and disease-free survival between these two subtypes in PCNSL DLBCL reflecting a different clinical behavior compared to its systemic counterpart. Several other variables as per the International Extranodal Lymphoma Study Group may play a role such as age, performance status, CSF protein, LDH level, and involvement of deep brain structures. ${ }^{[46]}$ The high prevalence of non-GCB phenotype with MUM1 positivity could explain the uniformly poor prognosis of PCNSL compared to its systemic counterpart. 
Table 3: Percentage of non GCB/ABC by immunophenotype in published cases of PCNSL

\begin{tabular}{|c|c|c|c|c|}
\hline Study & No. of cases & Markers used & Of non GCB/ABC phenotype (\%) & MUM1+ve \\
\hline Braaten, $2003^{[24]}$ & 33 & CD10, Bcl-6, MUM1, CD138 & 96.9 & $31 / 32$ \\
\hline Broet, et al., 2006 ${ }^{[5]}$ & 83 & CD10, Bcl-6, MUM1, CD138 & 96.3 & $75 / 81$ \\
\hline Lin, et al., 2006 25$]$ & 51 & MUM1, VS38C, CD138, bcl2 & 84 & $43 / 51$ \\
\hline Bhagavathi, et al., $2008^{[6]}$ & 21 & CD10, bcl6, MUM1, bcl2 & 90.5 & $19 / 21$ \\
\hline Cheng, et al., 2008 ${ }^{[26]}$ & 47 & CD10, bcl6, MUM1, Fox P1 & 91.5 & $43 / 47$ \\
\hline Levy, et al., 2008 ${ }^{[27]}$ & 38 & CD5, CD10, bcl2, bcl6, MUM1 & 87 & $17 / 18$ \\
\hline Haltab, et al., 2010[28] & 31 & CD10, Bcl-6, MUM1, and Ki-67 & 84 & $26 / 31$ \\
\hline Momota, et al., 2010 & 27 & CD5, CD10, Bcl-6, MUM1 & 81.5 & $22 / 24$ \\
\hline Kinoshita, et al., $2010^{[30]}$ & 32 & CD10, Bcl-6, MUM1, CD138 & 84.4 & $27 / 32$ \\
\hline Raoux, et al., 2010[40] & 39 & CD10, Bcl6 and MUM1/IRF-4 & 74.3 & $26 / 39$ \\
\hline Aki, et al., 2013 & 39 & $\begin{array}{l}\text { CD3, CD10, CD20, bcl-2, } \\
\text { bcl-6, MUM1, and ki-67 }\end{array}$ & 84.3 & $30 / 33$ \\
\hline Present series & 24 & CD10, Bcl-6, MUM1, CD138 & 91.6 & $22 / 24$ \\
\hline
\end{tabular}

GCB: Germinal center B cell, ABC: Activated B cell, PCNSL: Primary CNS lymphomas, MUM1: Multiple myeloma oncogene-1

In earlier studies, BCL-6 expression was reported to be associated with favorable survival ${ }^{[24,25]}$ but had unfavorable survival in another small study of 14 patients. ${ }^{[11]}$

Although EBV is present almost uniformly in AIDS-associated PCNSL, ${ }^{[34,35]}$ the virus seems to have no role in the pathogenesis of PCNSL in the immunocompetent subjects. ${ }^{[27,33,35-38]}$ In the present study also, all tumors were negative for EBV by ISH for EBER and immunohistochemistry for LMP1 antigen. This suggests that other etiologic factors are operative in PCNS DLBCL in the immunocompetent individuals. Other than JCV, which has been implicated in some cases of PCNSL, the involvement of other viruses in the pathogenesis of PCNSL has been reasonably excluded..$^{[4]}$

In conclusion, PCNS DLBCL in the immunocompetent is a unique clinicopathological entity which usually has centroblastic morphology and a non-GCB/ABC immunophenotype with almost universal expression of MUM1 and frequent co-expression of MUM 1 and bcl6. It does not appear to be associated with EBV, regardless of geographic origin.

\section{Acknowledgements}

The authors wish to gratefully acknowledge the clinicians from various Institutes and hospitals in South India who referred the cases to our Institute for histopathological diagnoses. We also wish to acknowledge the assistance of Mrs. Rajasakti V, Mr. Prasanna Kumar, Mr. Shivaji Rao, staff of Human Brain Tissue Repository (Brain Bank), and Mr. Manjunath K, Department of Neuropathology, National Institute of Mental Health and Neurosciences, Bangalore for assistance in histological preparation and microphotographs.

\section{References}

1. Kluin PM., Deckert M, Ferry JA. Primary diffuse large B-cell lymphoma of the CNS. In: Swerdlow SH, Campo E, Harris NL, Jaffe ES, Pileri SA, Stein $\mathrm{H}$, et al., editors. WHO Classification of Tumors of Haematopoeitic and Lymphoid Tissues. $4^{\text {th }}$ ed. Lyon: IARC; 2008. p. 240-1.

2. Morgello S. Pathogenesis and classification of primary central nervous system lymphoma: An update. Brain Pathol 1995;5:383-93.

3. Feuerhake F, Baumer C, Cyron D, Illerhaus G, Olschewski M, Tilgner J, et al. Primary CNS lymphoma in immunocompetent patients from 1989 to 2001: A retrospective analysis of 164 cases uniformly diagnosed by stereotactic biopsy. Acta Neurochir (Wien) 2006;148:831-8.

4. Montesinos-Rongen M, Siebert R, Deckert M. Primary lymphoma of the central nervous system: Just DLBCL or not? Blood 2009;113:7-10.

5. Camilleri-Broët S, Crinière E, Broët P, Delwail V, Mokhtari K, Moreau A, et al. A uniform activated B-cell-like immunophenotype might explain the poor prognosis of primary central nervous system lymphoma: Analysis of 83 cases. Blood 2006;107:190-6.

6. Bhagavathi S, Sharathkumar A, Hunter S, Sung L, Kanhere R, Venturina MD, et al. Activated B-cell immunophenotype might be associated with poor prognosis of primary central nervous system lymphomas. Clin Neuropathol 2008;27:13-20.

7. Gavrilovic IT, Hormigo A, Yahalom J, DeAngelis LM, Abrey LE. Long-term follow-up of high-dose methotrexate-based therapy with and without whole brain irradiation for newly diagnosed primary CNS lymphoma. J Clin Oncol 2006;24:4570-4.

8. Alizadeh AA, Eisen MB, Davis RE, Ma C, Lossos IS, Rosenwald A, et al. Distinct types of diffuse large B-cell lymphoma identified by gene expression profiling. Nature 2000;403:503-11.

9. Rosenwald A, Wright G, Chan WC, Connors JM, Campo E, Fisher RI, et al; Lymphoma/Leukemia Molecular Profiling Project. The use of molecular profiling to predict survival after chemotherapy for diffuse large-B-cell lymphoma. N Engl J Med 2002;346:1937-47.

10. Hans CP, Weisenburger DD, Greiner TC, Gascoyne RD, Delabie J, Ott G, et al. Confirmation of the molecular classification of diffuse large B-cell lymphoma by immunohistochemistry using a tissue microarray. Blood 2004;103:275-82.

11. Chang CC, McClintock S, Cleveland RP, Trzpuc T, Vesole DH, Logan B, et al. Immunohistochemical expression patterns of germinal centre and activation B-cell markers correlate with prognosis in diffuse large B-cell lymphoma. Am J Surg Pathol 2004;28:464-70.

12. Seki R, Ohshima K, Fujisaki T, Uike N, Kawano F, Gondo H, et al. Prognostic impact of immunohistochemical biomarkers in diffuse large B-cell lymphoma in the rituximab era. Cancer Sci 2009;100:1842-7.

13. Ilić I, Mitrović Z, Aurer I, Basić-Kinda S, Radman I, Ajduković R, et al. Lack of prognostic significance of the germinal-center phenotype in diffuse large B-cell lymphoma patients treated with CHOP-like chemotherapy with and without rituximab. Int J Hematol 2009;90:74-80. 
14. Nyman H, Jerkeman M, Karjalainen-Lindsberg ML, Banham AH, Leppä S. Prognostic impact of activated B-cell focused classification in diffuse large B-cell lymphoma patients treated with R-CHOP. Mod Pathol 2009;22:1094-101.

15. Laszlo D, Pruneri G, Andreola G, Radice D, Calabrese L, Rafaniello PR, et al. Tissue microarrays in diffuse large B-cell lymphomas: Are they really able to identify distinct prognostic groups in lymphomas of both nodal and extranodal origin? Int J Surg Pathol 2011;19:417-24.

16. Alacacioglu I, Ozcan MA, Ozkal S, Piskin O, Turgut N, Demirkan F, et al. Prognostic significance of immunohistochemical classification of diffuse large B-cell lymphoma. Hematology 2009;14:84-9.

17. Colomo L, López-Guillermo A, Perales M, Rives S, Martínez A, Bosch F, et al. Clinical impact of the differentiation profile assessed by immunophenotyping in patients with diffuse large B-cell lymphoma. Blood 2003;101:78-84.

18. de Jong D, Xie W, Rosenwald A, Chhanabhai M, Gaulard P, Klapper W, et al. Immunohistochemical prognostic markers in diffuse large B-cell lymphoma: Validation of tissue microarray as a prerequisite for broad clinical applications (a study from the Lunenburg Lymphoma Biomarker Consortium). J Clin Pathol 2009;62:128-38.

19. Carbone A, Gloghini A, Larocca LM, Capello D, Pierconti F, Canzonieri V, et al. Expression profile of MUM1/IRF4, BCL-6, and CD138/syndecan-1 defines novel histogenetic subsets of human immunodeficiency virus-related lymphomas. Blood 2001;97:744-51.

20. Meyer PN, Fu K, Greiner TC, Smith LM, Delabie J, Gascoyne RD, et al. Immunohistochemical methods for predicting cell of origin and survival in patients with diffuse large B-cell lymphoma treated with Rituximab. J Clin Oncol 2011;29:200-7.

21. Natkunam Y, Farinha P, Hsi ED, Hans CP, Tibshirani R, Sehn LH, et al. $\mathrm{LMO} 2$ protein expression predicts survival in patients with diffuse large B-cell lymphoma treated with anthracyclline-based chemotherapy with and without rituximab. J Clin Oncol 2008;26:447-54.

22. Montesinos-Rongen M, Brunn A, Bentink S, Basso K, Lim WK, Klapper W, et al. Gene expression profiling suggests primary central nervous system lymphomas to be derived from a late germinal centre B cell. Leukemia 2008;22:400-5

23. Rubenstein JL, Fridlyand J, Shen A, Aldape K, Ginzinger D, Batchelor T, et al. Gene expression and angiotropism in primary CNS lymphoma. Blood 2006;107:3716-23.

24. Braaten KM, Betensky RA, de Leval L, Okada Y, Hochberg FH, Louis DN, et al. Bcl-6 expression predicts improved survival in patients with primary central nervous system lymphoma. Clin Cancer Res 2003;9:1063-9.

25. Lin CH, Kuo KT, Chuang SS, Kuo SH, Chang JH, Chang KC, et al. Comparison of the expression and prognostic significance of differentiation markers between diffuse large B-cell lymphoma of central nervous system origin and peripheral nodal origin. Clin Cancer Res 2006;12:1152-6

26. Cheng J, Tu P, Shi QL, Zhou HB, Zhou ZY, Zhao YC, et al. Primary diffuse large B-cell lymphoma of the central nervous system belongs to activated B-cell-like subgroup: A study of 47 cases. Zhonghua Bing Li Xue Za Zhi 2008;37:384-9.

27. Levy O, Deangelis LM, Filippe DA, Panageas KS, Abrey LE. Bcl-6 predicts improved prognosis in primary central nervous system lymphoma. Cancer 2008;112:151-6.

28. Hattab EM, Martin SE, Al-Khatib SM, Kupsky WJ, Vance GH, Stohler RA, et al. Most primary central nervous system diffuse large B-cell lymphomas occurring in immunocompetent individuals belong to the nongerminal center subtype: A retrospective analysis of 31 cases. Mod Pathol 2010;23:235-43.

29. Momota H, Narita Y, Maeshima AM, Miyakita Y, Shinomiya A, Maruyama T, et al. Prognostic value of immunohistochemical profile and response to high-dose methotrexate therapy in primary CNS lymphoma. J Neurooncol 2010;98:341-8.

30. Kinoshita M, Hashimoto N, Izumoto S, Okita Y, Kagawa N, Maruno M, et al. Immunohistochemical profiling by B-cell differentiation status of primary central nervous system lymphoma treated by high-dose methotrexate chemotherapy. J Neurooncol 2010;99:95-101

31. Shia AK, Gan GG, Jairaman S, Peh SC. High frequency of germinal centre derivation in diffuse large B cell lymphoma from Asian patients. J Clin Pathol 2005;58:962-7.

32. Shiozawa E, Yamochii-Onizaka T, Takimoto M, Ota H. The GCB subtype of diffuse large B-cell lymphoma is less frequent in Asian countries. Leuk Res 2007;31:1579-83.

33. Camilleri-Broët S, Martin A, Moreau A, Angonin R, Hénin D, Gontier MF, et al. Primary central nervous system lymphoma in 72 immunocompetent patients: Pathologic findings and clinical correlations. Groupe Ouest Est d'étude des Leucénies et Autres Maladies du Sang (GOELAMS). Am J Clin Pathol 1998;110:607-12.

34. Forsyth PA, DeAngelis LM. Biology and management of AIDS-associated primary CNS lymphomas. Hematol Oncol Clin North America 1996;10:1125-34.

35. Bergmann M, Blasius S, Bankfalvi A, Mellin W. Primary non-Hodgkin lymphoma of the CNS-proliferation, oncoproteins and Epstein-Barr-virus. Gen Diagn Pathol 1996;141:235-42.

36. Krogh-Jensen M, Johansen P, D'Amore F. Primary central nervous system lymphomas in immunocompetent individuals: Histology, Epstein-Barr virus genome, Ki-67 proliferation index, p53 and bcl-2 gene expression. Leuk Lymphoma 1998;30:131-42.

37. Rao CR, Jain K, Bhatia K, Laksmaiah KC, Shankar SK. Association of primary central nervous system lymphomas with the Epstein-Barr virus. Neurol India 2003;51:237-40.

38. Tandon A, Challa S, Shanmugham M, Gopalan S, Paul RT, Digumarthi R. Epstein-Barr virus as a possible etiologic agent in primary central nervous system lymphoma in immunocompetent individuals. Neurol India 2009;57:36-40.

39. Pileri SA, Dirnhofer S, Went P, Ascani S, Sabattini E, Marafioti T, et al. Diffuse large B-cell lymphoma: One or more entities? Present controversies and possible tools for its subclassification. Histopathology 2002;41:482-509.

40. Raoux D, Duband S, Forest F, Trombert B, Chambonnière ML, Dumollard JM, et al. Primary central nervous system lymphoma: Immunohistochemical profile and prognostic significance. Neuropathology 2010;30:232-40.

41. Aki H, Uzunaslan D, Saygin C, Batur S, Tuzuner N, Kafadar A, et al. Primary central nervous system lymphoma in immunocompetent individuals: A single center experience. Int J Clin Exp Pathol 2013;6:1068-75. Print 2013.

42. Saito M, Gao J, Basso K, Kitagawa Y, Smith PM, Bhagat G, et al. A signaling pathway mediating downregulation of BCL6 in germinal centre B cells is blocked by BCL6 gene alterations in B cell lymphoma. Cancer Cell 2007;12:280-92.

43. Liu YH, Xu FP, Zhuang HG, Lai KC, Xie D, Luo DL, et al. Clinicopathologic significance of immunophenotypic profiles related to germinal center and activation B-cell differentiation in diffuse large B-cell lymphoma from Chinese patients. Hum Pathol 2008;39:875-84.

44. Barrans SL, Carter I, Owen RG, Davies FE, Patmore RD, Haynes AP, et al. Germinal center phenotype and bcl-2 expression combined with the International Prognostic Index improves patient risk stratification in diffuse large B-cell lymphoma. Blood 2002;99:1136-43.

45. McClintock S, Perkins SL, Cleveland RP, Trzpuc T, Vesole DH, Logan B, et al. Immunohistochemical expression pattern of germinal center and activation B-cell markers correlates with prognosis in diffuse large B-cell lymphoma. Mod Pathol 2003;16:244.

46. Ferreri AJ, Blay JY, Reni M, Pasini F, Spina M, Ambrosetti A, et al. Prognostic scoring system for primary CNS lymphomas: The International Extranodal Lymphoma Study Group experience. J Clin Oncol 2003;21:266-72.

47. Paulus DM. Malignant lymphoma. In: Louis DN, Ohgaki H, Wiestler OD, Cavenee WK, editors. WHO Classification of Tumours of the Central Nervous System. $4^{\text {th }}$ ed. Lyon: IARC; 2007. p. 188-92.

How to cite this article: Mahadevan $A$, Rao $C R$, Shanmugham $M$, Shankar SK. Primary central nervous system diffuse large B-cell lymphoma in the immunocompetent: Immunophenotypic subtypes and Epstein-Barr virus association. J Neurosci Rural Pract 2015;6:8-14.

Source of Support: Nil. Conflict of Interest: None declared. 